\title{
OPENING SPACES FOR THE DEVELOPMENT OF HUMAN AGENCY WITH PROBLEM BASED LEARNING IN PALESTINIAN HIGHER EDUCATION.
}

\author{
First Author ${ }^{1}$ Karl Royle
}

${ }^{1}$ University of Wolverhampton, Wolverhampton, UK

\begin{abstract}
This paper appraises the impact of Problem Based Learning (PBL) implementations within the (2016-19) Erasmus Plus "Methods" Project (Modernization of Teaching Methodologies in Higher Education: EU experience for Jordan and Palestinian territory) which introduced a range of learning modalities into formal learning contexts in higher education settings in Jordan (4 Universities) and Palestine (4 Universities). The project was jointly led by the Universities of Jordan and Birzeit, Palestine and there were six European partner universities. The paper focuses on the impact of PBL approaches on learners and university teachers through an analysis of semi-structured group interviews with students and individual staff interviews across a range of courses in the arts and sciences within the Palestinian context. The results of this small-scale research study are presented within a thematic framework focusing on participation, collaboration, agency, knowledge creation, problem solving and identity modification. It explores how far the adoption of student-centred PBL designs can open spaces for the development of human agency and capabilities within an existing orthodoxy of practice in Higher Education Settings in Palestine. It locates these student-centred practices within the context of higher education under occupation and examines what contribution they make to developing individuals' capacity to act effectively for change within the power dynamics and limits of their context.
\end{abstract}

Keywords: Problem based learning, Human agency, Participatory practice.

\section{Introduction}

The Methods project's overarching objective was "To raise the competencies of individual learners to become active members of the knowledge society by enhancing the learning process of students acquiring $21^{\text {st }}$ Century competencies to become autonomous learners through EU experience". The project was initially concerned with introducing educational technology and e-learning approaches to augment existing practice based on Moodle learning management systems. To balance this approach a professional development programme was codesigned to introduce different learning "modalities". The phrase "EU experience" was problematised and reformed into a knowledge exchange, co-production framework based on equality of experience rather than knowledge transfer based on a perceived gradient of expertise. Three main modalities were adopted, PBL, flipped learning (that was problem based) and the creation of learning resources to support Massive Open Online Course (MOOC) development. The project introduced different collaborative learning approaches within the confines of an orthodox system that was, like its European counterparts, predicated upon standardisation of outcome, lectures and knowledge tests. The paper focuses on the response of learners and teachers to the introduction of problem-based learning within four Palestinian universities across 12 courses ranging from teacher education to computer engineering. It draws briefly on two online surveys (the subject of a separate paper) which highlighted an attitudinal shift in preferred learning approaches amongst participating students which prompted a further qualitative study (the subject of this paper) comprising a series of semi-structured group and individual interviews with staff and students at each university. These were conducted to answer the research question: What evidence is there that PBL and Flipped PBL methodologies give rise to a range of behaviours that can develop autonomy and agency within and outside the learning environment? The Palestinian development context is characterised by low graduate employment and outsourced working, coupled with restrictions on travel both into and out of the West Bank and also within the West Bank itself. This can result in very localised university populations as travel, even over relatively short distances, can take many hours due to checkpoints and other restrictions, (Yaha 2016). The exercise of power over the Palestinian people by the occupation permeates directly and indirectly into the lives and activities of students and lecturers. Learning designs that create agency and autonomy of thought are arguably crucial within this dynamic to actively develop Palestinian society.

\section{Background and Context}

Defining PBL in the Methods project 
PBL was a chosen methodology within the project because of its ability to shift learning designs from the didactic to more student-centred approaches. As such it invites students to become self-organising and to work together on "authentic" problems. Outcomes, in the most agentic forms of PBL can be divergent and are not predetermined. They also have an emphasis on process as much as product, how people engage and participate is often as important as the solution arrived at. The key principles employed in the Methods project, were based on the work of (De Graaf and Kolmos, 2003). This includes a problem definition process coupled to learner selfdirection; activity based learning and decision making based on interdisciplinary 'real world' complex problems; and group based activities so that personal competencies are developed and students learn to handle the process of co-operation in all its stages, (p. 658). Introducing PBL in the Palestinian context entailed a fundamental shift in learning design from objective led, content heavy approaches to looser, more open patterns of student engagement and participation. The training element for Palestinian Lecturers was delivered by the University of Aalborg see fig 1 below after Magnussen (2016) (Methods Project Documents). The framework was very adaptive to the Palestinian context because it stressed that PBL can be more or less student controlled and more or less group oriented. The Aalborg model allowed a range of approaches to be adopted by lecturers that could be readily adapted to fit their particular learning context.

\section{PROBLEM BASED LEARNING AT $\mathrm{AAU}_{3 / 3}$}

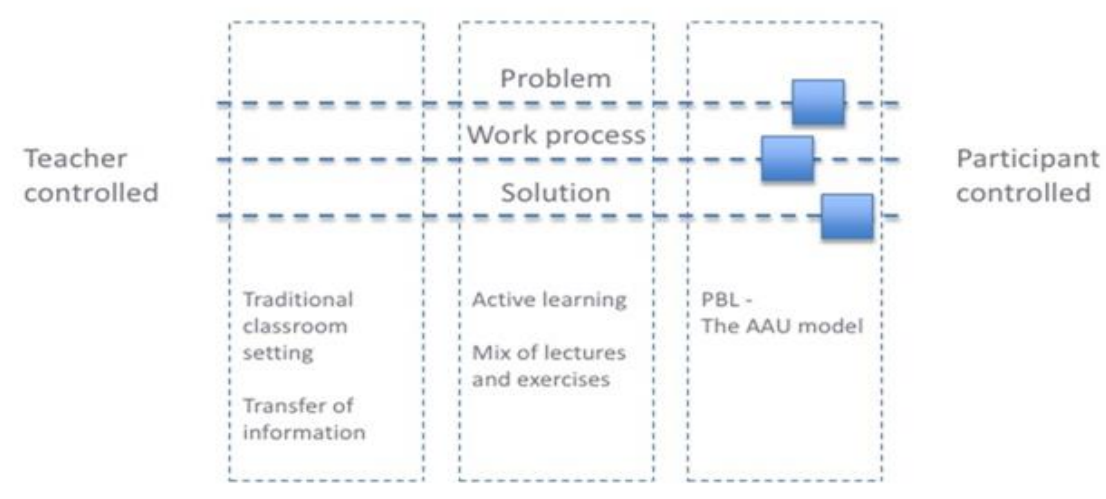

Fig 1. Problem based learning design model.

\section{Opening space for change}

Palestinian education is bounded by the power relationships with the occupier and it is understandable that conforming to academic norms and 'standards' is important, especially where comparisons may be drawn with others. Change in any environment comes with risk and this is perhaps why methodologies become fixed/orthodox in spite of the fact that other forms of education may address the context of occupation more effectively. Deleuze and Guttari's (1987) notion of smooth (nomad) and striated (state) spaces is useful for thinking about the effect of pedagogies such as PBL on an institution's instructional norms. Bayne (2004) puts it most succinctly: "Smooth space is informal and amorphous, striated space is formal and structured. Striated space is associated with arboreal, hierarchical thought, ... opposed to rhizomatic thought - non-hierarchical, underground, multiply-connected. "(Bayne 2004, p. 303)

In this case, the existing practice of a lecturer mediating knowledge in an ordered way with predetermined outcomes is representative of striated space whereas participatory approaches such as PBL can be considered to possibly open a space within which learners can explore a variety of directions and collaborations (smooth space) resulting in diverse outcomes. However, one might equally argue that PBL just replaces one striation with another, "smooth space is constantly being translated, transversed into a striated space; striated space is constantly being reversed, returned to a smooth space. (Deleuze \& Guattari, 1987, p. 474)

It is the 'stent' like quality of PBL formats and frameworks, to open space for flows of difference, criticality and creative thought within the striated orthodoxy, that is attractive. Savin-Baden (2014) describes PBL practices and proposes an ontology of five curriculum types ranging from type one - Striated - highly bounded and controlled, which might in this case represent the orthodoxy where the type of learning is "routine, preparation and rehearsal" and moves to type five Connectivist (learning through making connections). Types 
two, Borderland- control with open endedness and three, Smooth- open, flexible and contested spaces and four Troublesome, where learning is based on dealing with disjunction and uncertainty, perhaps best summarise the how PBL models can and do affect change in learning design and the nature of student engagement. SavinBaden (2014), also supports the notion that PBL methodologies can open spaces that scaffold the release of personal and collective agency through self-organisation. According to Den Bossche, Gijselaers, Segers, \& Kirschner (2006) students work together in such spaces to develop solutions to emerging problems through co-construction of meaning, convergent and divergent discussions, listening and negotiation. It is interesting in some cases to note how the activities and behaviours enabled by the methods project became physically manifest. In the before and after (PBL) photographs (Fig 2) below of a classroom layout we can see on the left a scene that is not out of place in any University. The lecture chairs in rows, designed for listening and writing and increasing classroom occupancy, explicitly illustrates what Monahan (2002) calls 'built pedagogy. "A classroom with neat rows of desks embodies pedagogies or "tacit curricula" of discipline and conformity, whereas spaces personifying flexible properties ... can be said to embody pedagogies of freedom and selfdiscovery”. (Monahan, 2002, p.5)
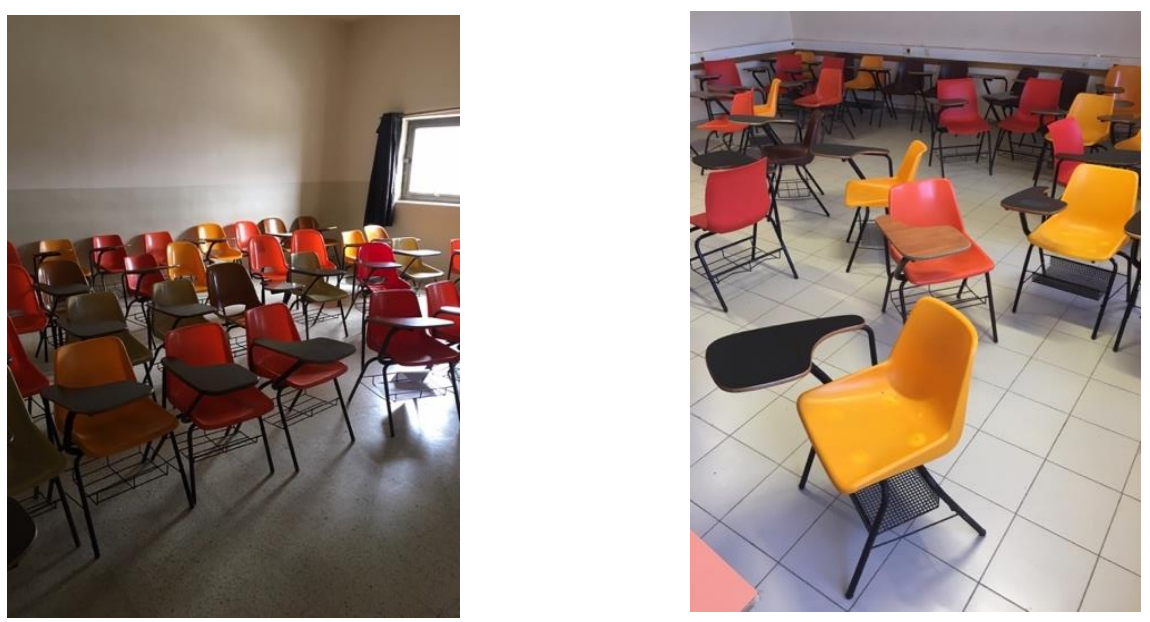

Fig 2. Before and after PBL at Birzeit University, Ramallah, Palestine: Electronic Engineering Group.

\section{Agency in the context of power relationships.}

In the Palestinian context, developing human agency, (Bandura 2001), through learning designs that give people a measure of control over their own functioning and environmental events, are arguably to be valued above those that are directed and managed monocratically with little room for diversity of approach or outcome. Agency, is often aligned in educational terms with the notion of perceived self-efficacy, defined by Bandura (1982) as being concerned with judgments of how well one can execute courses of action required to deal with prospective situations. Cauce and Gordon (2013) note those with a strong sense of self-efficacy are most likely to persist in the face of failure. Therefore, it follows that self-efficacy can be brought about by practice and by putting people into situations where failure and overcoming failure through perseverance are part of success in any endeavour. Within any context, there are limits within which agency can be applied. Sen's (1985) notion of agency freedom refers to "what a person is free to do and achieve in pursuit of whatever goals and values he or she regards as important" (Sen,1985, p. 203) and this greater resonance within the context of occupation. Tobias (2005) rightly cautions against adopting a liberal acceptance of "freedom to choose". "The reification of agential freedom abstracts from the concrete context and conditions under which chosen ends can be effectively pursued. “(Tobias, 2005, p.70)

Whilst the spaces within which we work, live and learn are striated, education that allows us to critically assess the fabric of those rules and striations is valuable in developing individuals who are inventive in the face of adversity and are open and responsive to constructing a change in possibilities and circumstances. Palestinian students are resilient when faced with the random restrictions of the occupation, as a lecturer at Bethlehem University (2018 Interview transcript.) notes, "In Palestine you are going to have days where movement is very difficult, but we need to continue. We live in a precarious environment." Students from Birzeit University (Methods Project Report) also voice similar issues: "Sometimes they (Israel) close the roads so we can't go (to the university). Last year, because of the intifada ... Those that come from Jerusalem could not reach the campus safely." A constraint on agency is arguably connected to the constructs of power and control that pervade any context. Foucault's discussion of power and agency is highly relevant here. Foucault's (1975) notion of education as being part of the extension of social control whereby we police ourselves through 
our own institutions and we fabricate docile citizens through education would seem to obviate the very notion of human agency. As Palestine is constantly surveilled and has been described by Pappe (2017) as the 'Biggest Prison on Earth' it is particularly difficult to counter this through notions of agency freedom, Sen (1985). As Leask (2012) notes, Foucault likens education to the panopticon of the prison where there are "processes for controlling space, for programming and scheduling time, for compiling data and records, and for employing ever-improving methods of surveillance." (Leask, 2012, p.58) Foucault's later work however, according to (Leask 2012), advocates that there is always the possibility for change in the dynamics of power and that that change is brought about by the agency of individuals.

"The possibility now emerges that it can also be the theatre of subjects' creation of new 'practices of self', new kinds of relations - especially via continued resistance to domination. (...) Teachers and students alike can now be regarded as creative agents, capable of voluntary and intentional counter-practices, and always able, in principle, to resist aspects of the kinds of managerialism, instrumentalization and commodification they face daily, and to construct strategic interventions." (Leask, 2012, p. 67)

Further, one can note after Foucault (2000), that whilst we are never free of power relations and cannot jump outside them, - the Palestinian is not free from occupation, the student (and teacher) are not free from examination and grading, - these things can always be changed. As Leask (2012) notes, quoting Foucault, "“We are always free'; we can always resist; our ongoing task is to construct 'arts of living' that might counter the manifold expressions of 'fascism' that lurk throughout institutions, systems, relations, and even ourselves," (Leask, 2012, p.67). The following sections will detail how far PBL interventions in the Methods project have created change within the confines of the institutions involved.

Method. A mixed methods approach, using survey responses as a catalyst for further qualitative group and individual interviews (Mertens, 2018) was used to gain further insight into the effect of PBL across a range of stakeholders and their accumulated body of knowledge about their lived experience of the intervention/learning design. (Chilisa, 2005). The validity of the qualitative research process is constrained in part in that participants in semi structured group interviews were selected by the course leaders as members of the courses that included PBL for the first time. Equally, because of the distributed nature of participants and travel restrictions (see previously) little co design of the research could be undertaken. However, most students had completed their courses so were under no pressure to report favourably and were assured of anonymity of response by the research team. Staff were also interviewed separately using semi-structured interviews. Although most participants had a good standard of English two researchers were engaged in the process so that Arabic could be used to elaborate points and as the primary medium where required. Semi-structured group interviews were therefore conducted bilingually. The researchers were also aware of the cultural context of education in Palestine and the continuing occupation and history of the Palestinian people. The researchers were aware that the voice of students was particularly important in this project so that future policy might be set with their contributions in mind.

Initial Surveys. Two online surveys were used with all participants in both Jordanian and Palestinian Universities, these were a "Digital Habits" survey /single time point, see ( Ozdamar-Keskin, N., Ozata, F.Z., Banar, K. and Royle, K 2015) and an impact evaluation survey after Kirkpatrick (1996) which had two time points . Time point one involved questions about reactions and learning, whereas timepoint two looked at changes in behaviour and longer lasting impacts (results). These surveys are the subject of a later paper and so only the initial findings that prompted this further investigation are reported here. The impact evaluation surveys also focused on students' direct experience of the methods courses and their learning preferences and any change in learning preferences as a direct result of a methods course. Numbers of respondents: Time point 1: Total respondents $=1433$ (Jordanian Universities $=997$, Palestinian Universities $=436$ ). Time point 2. Total respondents $=1407$ (Jordanian Universities $=1179$, Palestinian Universities $=228$ ). The time points were 3 months apart and although the cohort was the same the number of respondents had fallen because they were no longer taking the same courses and were only reached by email. This was particularly true of Palestinian participants who had mostly taken electives or who had been final year students.

Students from Palestinian Universities seemed to express more confidence, competence, and utilisation of independent learning skills through these self-report surveys than Jordanian Students. Using descriptive statistics only the Jordanian result showed a shift between $\mathrm{T} 1$ and $\mathrm{T} 2$ of $\approx 5 \%$ from individualised learning behaviours to a preference for more structured and lecture-led learning. Contrastingly, the Palestinian responses showed a decrease in these behaviours and an increase of $\approx 20 \%$ towards more collaborative learning behaviours. This suggested that the greater emphasis placed on problem-based learning /teaching methodologies 
by Palestinian Universities (605 students) / Jordanian Universities (190 students) may have influenced this change and as such was worthy of further investigation through qualitative interviews.

Forming the framework for the focus groups and interviews. The initial three learning modalities were developed and adapted to the varied contexts for learning and teaching in Jordan and Palestine. These modalities were further defined through conversations with colleagues and through monitoring visits and project meetings. The following modalities were evident within practice.

E learning. Courses that used on line learning with online discussion and occasional face to face contact were concerned with compulsory courses with high numbers $(250+)$ of students.

Flipped learning was defined as tasks set outside of class and then discussed face to face in class. This involved the provision of online materials within the Virtual Learning Environment system or on You Tube that students would review at home before coming to class. This was a departure from previous classes which would involve lectures and practice.

MOOC: The MOOC concept was primarily used as a form of online learning that sought to incorporate the best aspects of collaborative face to face learning but more often than not fell into the arena of content with tests in a behaviourist style.

Flipped/ PBL. Here the modality gave students challenges in terms of group-based research where they were directed to online resources in order to solve a problem which was more open ended. This was quite a radical departure for many lecturers and it often required a change in assessment methods. This was classified as the "challenge based" flip.

PBL: Where PBL was used this required greater student autonomy. It was purely, group and challenge led but was facilitated with varying degrees of scaffolding by the tutors involved. It invariably needed a change in assessment to facilitate the change in pedagogical approach. Students tended to choose their own way of communicating and used their own devices.

These modalities were placed onto a revised SAMR, (Puentedura 2009) model in order to project how the learning modalities might affect teaching practice and engagement. The SAMR model has been revised by others (Hamilton, Rosenberg and Akcaoglu 2016) and aligned with other models such as Bloom's Digital Taxonomy by the originator, (Puentedura, 2014). The model itself is appealing in its simplicity but is essentially based on the effects of technology integration into teaching and learning. Other approaches such as Technology, Pedagogy, Content, Knowledge (TPCAK) (Koehler \&. Mishra 2009) focus on the teacher's relationship with a variety of variables. What we create here is an attempt to place the methods modalities at the centre of the learning transformation and focus on what effect that might have on student engagement. The original SAMR model (Fig 3.) places the focus on what kind of learning can be created by introducing digital technology whereas we looked at the anticipated levels of engagement, agency, creativity and collaboration produced by the learning design where digital technology was seen as an integral tool but not central to learning change. The 'technology' in this case was the learning design itself. (Royle and Nikolic 2016)

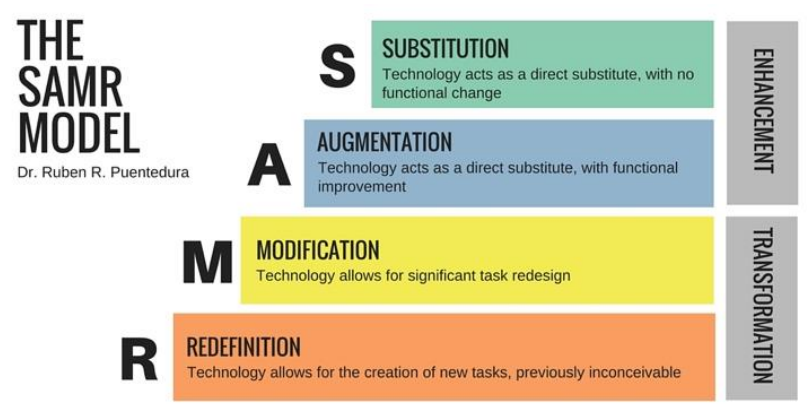

\section{Fig 3. The original SAMR model: CC by Attribution-ShareAlike 4.0}

The revision below (Fig 4) (constructed with colleagues at a project meeting: (Jordan January 2018)) was used as a working model to describe the learning designs and their possible effects in the Methods Project. Whilst the emphasis in the original SAMR model is on the position of technology as the change agent here we look at the teaching and learning modality, its relationship to technology and its possible effects on learning. 

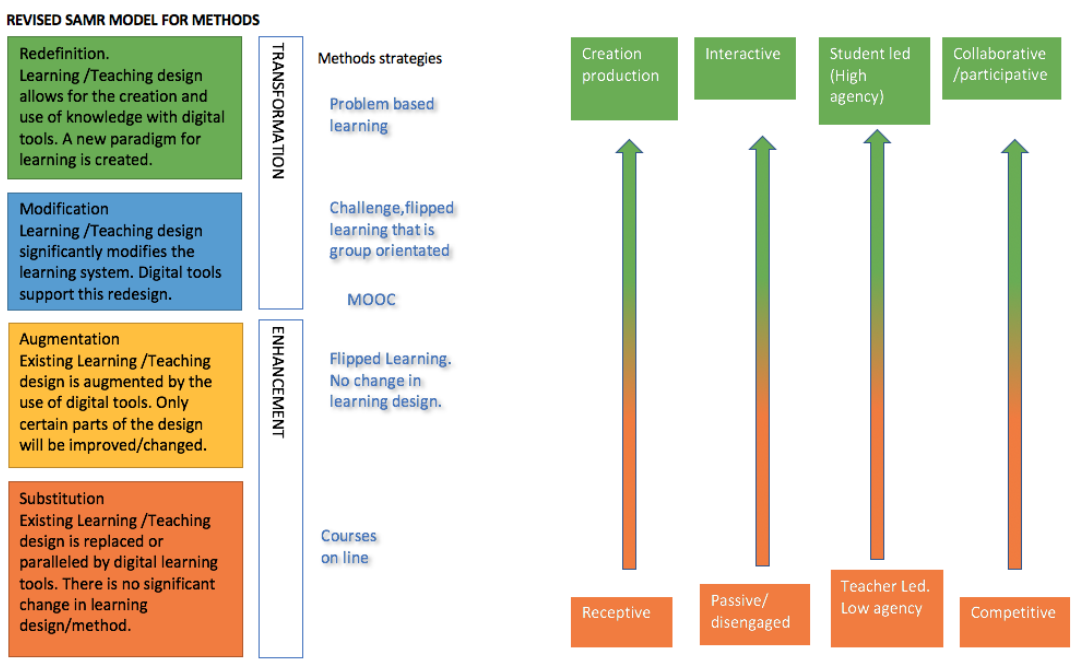

Fig 4 Revised SAMR model focusing on learning design and learner engagement.

This revised model proposes that PBL and Flipped PBL methodologies can be transformational in developing a range of behaviours that develop autonomy and agency within and outside the learning environment. Autonomy is used here an overarching "label" for a range of behaviours one would expect to be present (according to the literature) within problem-based learning. This is not to say that digital technology is not important in enabling pedagogical change and in some instances in the Palestinian context it is also vital to mitigate structural issues around physical attendance in a precarious security situation.

Group interviews. This consensus mapping in the diagram above prompted the design of an interview framework based on the following themes. Agency: defined as, the ability to exert control or freely make decisions based mainly on Bandura's (2006) definition of four core properties of human agency. Collaboration: the basis for this was the range of skills needed for effective collaboration after Roselli (2016). Participation or taking part: the degree to which individuals discussed or engaged with more knowledgeable others, tutors or with peers. (Lee and McLoughlin, 2007), (Leadbetter and Wong2008) (Hampson, Patton and Shanks, 2011). Knowledge creation and transfer: As a part of the PBL process is to devise solutions to problems it was pertinent to interrogate the degree to which both students and tutors thought this had occurred. This could include, content creation and synthesis, metacognition, and learning from others. With problem-based strategies, (Thomas 2000), (Trilling and Fadel 2009), (Bransford 2004), all note the need for authenticity and real worldliness in the problems that are given or established by students, whilst Polya (1945) refers to some form of structure being used to plan, research, set goals, reflect and replan collectively. Finally, identity formation for both lecturers and students was considered as Osterlaken (2015) notes, when we change a learning design, we may also affect identities and roles.

Students from a range of Palestinian courses took part in semi structured group interviews based on a bespoke interrogative framework. Lecturers were interviewed individually to gauge their views on the effects of PBL. Students were interviewed over a three-day period in April 2018 and as such the sampling method was that of convenience. Although there are issues with this type of sampling it could be argued that the sample was a homogenous group and consisted of a mix of gender representative of the overall university populations of around $60 \%$ female, $40 \%$ male. Twenty seven students from different courses at four different Universities, Birzeit University (BZU) (Ramallah) five students, An Najah University (ANU)(Nablus) eight students, The Palestinian Polytechnic University (PPU) Hebron eight students and Bethlehem University (BU) six students, were interviewed in groups. These were cross subject groups in ANU and PPU and single subject groups in BZU and BU. Ten staff were also interviewed individually. Communication between the groups was not possible and it was interesting to note the similarities of response despite the variety of courses that the students were drawn from. Students and teachers from: Electronic Engineering (Birzeit); Systems Analysis and Computer Systems Engineering (Bethlehem); Teacher Education Bethlehem, Land Use Planning, Ecology, Literature, (An -Najah, Nablus) Methods of Scientific Research (Hebron), were interviewed and all courses were undergraduate. Initial responses were transcribed and then coded against the framework sections above carried out by the author. Secondary analysis was then undertaken where further subthemes were identified within each main framework theme. 


\section{Findings.}

Agency is at the heart of PBL. Its properties as defined by (Bandura 2006) include, intentionality (planning), forethought (goal setting), self-reactiveness (reacting to developments and ensuring plans are enacted and achieved - self-regulatory behaviour), and self-reflectiveness (how are we doing). Sub themes that emerged from student responses were: confidence; ownership of the process of learning and any consequent control that students felt they had over proceedings; collaboration; knowledge creation; authenticity; and sustainability.

\section{Confidence}

(By)Making applications in the real world not just doing something for the course, we saw the output. We are more confident because we can do stuff now. When I walk into a room now I can look at anything and understand how it works. BZU Student 1

In Bethlehem, confidence was equated with doing things rather than passive reception. This seemed to confirm the premise of the SAMR modification from passivity to engagement and a transfer of control to the student. "Didn't feel like students it made us more confident - we do things not receive them. I have become more confident in presentations and how to work with people." BU Student2. In Nablus (ANU) students spoke of "self confidence in my own abilities" and -Before this course I did not have the powers to stand and discuss with students. Now I can speak and discuss with others. We are more confident, we felt proud because we had achieved something. ANU Student 3. This feeling of increased confidence was also expressed in Hebron (PPU) where students felt more engaged and confident in their interaction with the subject. In terms of engaging with an 'active learning process' students spoke of the way in which technologies were used to enable the "new" way of learning.

The main point for me was to get rid of paper and use technologies. To use video was important for me not just to sit in the class and listen and write. We worked mostly face to face but also online, we used gdocs and, Facebook/WhatsApp. PPU Student 2

Others spoke more about their own personal control and freedom in the process of learning: acting and thinking in new ways and for themselves. A movement from teacher control to student control was expressed and students saw their experience as one of learning as much as being taught.

Systems analysis taught me research skills... I should look for information myself and not depend on teachers. This was really important for me. To think and build something on your own is important. BU Student 6 This way gave me higher grades and. I was able to be more effective when researching on other courses. My methodology of researching got better. BU Student 6. We see the lecturers as guides and this way we have more control and power. ANU Student 5

A theme related to self-regulatory behaviour, adapting to change and a test and learn mentality were evidenced in some responses. The point is applying and testing. It works-great you can apply it, if it doesn't work then okay, we will try something else. BU Student 6. In one case a student referred to their work in teaching literature in Palestinian schools by remarking that the PBL process had made them realise that. "Literature is not a smooth subject, it is rigid, and we try to open it and make it more accessible". Whilst this alludes to Deleuze and Guttari's (1987) notion of smooth (nomad) and striated (state) space and whilst perhaps only coincidental, it does illustrate that students are reflecting about the fabric and nature of their subject and testing how different approaches might open them to others.

Self-advocacy and voice were also evidenced across the PBL classes at different universities, the PBL learning design seemed to open space for speaking up and speaking out within the bounds of the subject.

In this kind of class, you do things, you give your voice, you write your opinion, you suggest, you make something, you say what you think and then if you think it is true you have to prove it through practice. BU Student 3. Inside the class you could speak freely. You can discuss and explore anything you want. Express yourself and give your opinions. ANU Student 4

Learning through failure and belief in one's own self efficacy and in not giving up at the first obstacle was also evident. There was an acceptance of "failure" as part of learning and as part of the process. We tested hypothesis as we practised so failure is part of the plan. BU Student 2. We didn't think about the grade only that we shouldn't quit. PPU Student 5. . Equally, an increase in perseverance emerged and a realisation that with a 
willingness to try and discover what worked in their context students could achieve results. We changed our output 5 times... either because we were giving the wrong solutions or the wrong causes for the problem. So we had to revise and do it again. BU Student 3 It was stressful in the beginning and it was a lot more work. When we understood what we were doing in this way it got better and less stressful. ANU Student 5

\section{Collaboration and participation in the learning process}

Teamworking and collaboration as a result of PBL also led to opportunities for negotiation, conflict resolution and mutual support. Students talked of negotiation and bringing other students up to speed with their ways of working. This also made them active participants in the learning process. We had discussions about what to do and all agreed after negotiation - We learned a new set of skills around practical and communication skills, we had to adapt to having a new partner who we had to train. BZU Student 1. New insights were gained into working collaboratively in teams and the students realised that they had to solve any problems that arose and use soft skills to do so. The team is most important and sometimes some members don't work but we solved it. You should try to choose your team well. - We had some issues but we made each other work. BU Student 6 (We learned)-By working in a team on a project we have to deal with many opinions. Dealing with others respectfully. PPU Student 4. However, team working was a mixed experience: Working with a group was harder than working by myself. ANU Student 8 Mutual support was also evident. For me this course improved my personality ... how to work with others...communication, conflict solving, co-operation. This made us more effective in group work- we learned more because we worked together... we helped students who were not advanced. ANU Student 2

As well as participating through collaboration in teams students also commented on how much more involved they were in classes. Increased participation (how far students take part and engage in class through discussion with peers and the lecturer and other points of connection, online or through research and texts) is a key aspect of pedagogical change. When a space for co-production is created, student generated knowledge which extends both their own learning and the lecturer's is key. Students also voiced perceived differences between other methods and the PBL experience.

In a regular class you just take whatever the teacher says, you don't understand the whole thing ... you only get about $70 \%$ of the information that you need to actually comprehend everything. You just sit in class and listen. In the methods project we contributed. ANU Student 5

We were more active as students and less passive. We are not receivers we are producers. PPU Student 6 They also commented on discussions and the benefits of working with the lecturers and students. We benefitted from every side. We worked with the lecturer and the students. We discussed the lecture with the students and solutions and causes. ANU Student 6 Each stage of the problem-based learning was discussed, and we got feedback from her (lecturer). Difficulties and improvements. It's the only class where I never felt bored. BU Student 3. There was also an expression of feelings. "It's fun" was mentioned regularly in the transcripts. It was fun, we had fun, it's a fun way to learn, across all the Universities and courses. Great also featured as an expression of feeling several times alongside "amazing". Sic:

It was really amazing, we had fun.

\section{Knowledge Creation}

This was evidenced through project outputs. Presenting and publishing results were seen as positive learning experiences as part of PBL. Making - that could be applied to social needs was a positive outcome for computer engineering students.

We are developing power supplies for every school for them to do stuff with it. It costs 115 dollars normally. To power up computers and projectors. We take the power supplies from old PC CPUs and convert them. Low cost and allows the school to use a power supply for different things. So we make this initiative for the people as a social obligation so we can give something back. To help them. BZU Student 5

One of the lecturers noted that students came up with several different solutions to a problem which wasn't the normal practice. At the end they all came with different solutions to the same problem which was great and unusual. Lecturer 3, BU. Ways of thinking were also purported to have changed:

We started to use critical thinking and started to think like an analyst to solve problems. BU Student 6

\section{Authenticity}

A key effect of PBL was the authenticity of the tasks, (De Graaf and Kolmos 2003), that were used which engaged students in the learning process. Birzeit students reported that they had extended their learning and 
skills to developing a start-up making power supplies for community organisations effectively transferring their knowledge from the classroom to a wider context. Even the act of co-ordinating activity became an authentic learning experience that replicated the world of work. It is difficult when you are cross disciplinary to get time together to complete projects. We used technology but we had to be together physically as a group too. PPU Student 1. Students scaffolded their work by planning and replanning and setting goals themselves. We had a plan and if things go wrong, we replan. - Yes, I got frustrated but then I carried on. BU Student 4. They remarked on the motivational aspects of having an authentic purpose. This was a theme throughout the interviews. Projects were grounded in the Palestinian context and had real outcomes. The theory became live and practice was hypothesised and tested.

We had a problem at the beginning of the course itself and we had to make a work plan. So this was based on actual general life problems and we had to make a work plan for how to solve it. Then from this point we had to make work plans for other problems related to the course.

We looked at global warming issues, so they were real. We looked at biodiversity and we came up with a good solution. BU Student 6

The realisation or theory through practical application also led to a degree of authenticity in that applying theory was seen as an effective learning strategy. I did not understand the concepts but when it was done in the practical sense it became easier for me. Getting knowledge about what you can't understand theoretically through practical work. This broke the barrier for me. BZU Student 5. Even subjects that are not really noted for their practical application were related to the Palestinian context of living in a pluralist society. The poems we studied - Blake and Wordsworth we looked at how people lost trust in religion and related this to our context. How the political system uses this to achieve their aims. And we can see that now. ANU Student 7

\section{Sustainability.}

One of the most positive drivers for change was that grades improved, and several lecturers expressed "pride" in their students' achievements and how much the students enjoyed the approach.

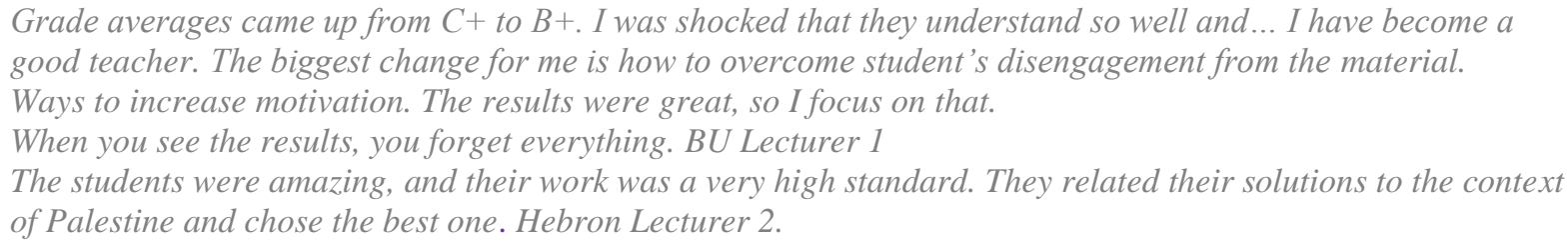

All lecturers interviewed felt they could spread the PBL method to other courses and some had already done so. It's becoming a way of teaching in other areas too, not structurally but it is spreading. ANU Lecturer 3. However, all said it was hard work and could not be done with large groups. This will probably be the next challenge to face - how does PBL become scaled and more importantly, does it need to be scaled?

It's hard for us, it takes a lot of work. It's easier for me to be a mono transmitter rather than a facilitator. You are involved in several projects and you are more involved in them and with the students. It's not easy for classical teachers to convert to this method. ANU Lecturer 3

\section{Conclusions and discussion}

Undoubtedly, where PBL was implemented it resulted in greater student engagement and agency. However, Bayne's (2001) notion of smooth space as being informal and amorphous and striated space being formal and structured does not quite fit with problem-based learning. Although PBL does open a space it appears to be more successful where it is scaffolded and control is released to students incrementally.

All lecturers without exception used some form of scaffolding of the experience. Some were more controlled than others. Some were content with providing a problem-solving rubric, materials and regular meetings for discussion where others created detailed assessment frameworks and project plans.

I then used PBL... gave structure to students and they worked in groups and each month they presented their work. Each group had a use case given by me and they applied it in their group. After 1 month they have to present the progress. They thought it was a lot of work. BU Lecturer 3.

Another lecturer used clearly defined stages to scaffold the work of the students. 
It was a lot of work for them, trying to identify problems, going into the community trying to test your solutions. They did it in three stages.

Stage 1 was id problems, stage 2 was finding solutions and testing them out, stage 3 was presenting what happened. I was able to meet them at each stage and guide them through...I also told them it was okay to fail. BU Lecturer 1

Each tutor had a different way of structuring the learning which were more or less "striated":

I give them directions to convert the problem definition into evaluation criteria for their solution at the end,(support the structure of the learning). BU Lecturer 3 This is much better for them. I had regular classes but only for project discussion. I advised them in these sessions. ANU Lecturer 1

\section{Identity}

In some cases, the PBL ethos extended the curriculum into the community where students were solving authentic needs. Students had practised and acquired a range of soft skills and in some cases claimed that they were thinking differently rather akin to Gee's (2005) conceptualisation of 'authentic professionalism' where experience transforms individuals into 'becoming' researchers or engineers or teachers. Students took on more professional positions in regard to how they thought of themselves and also around how they worked with their lecturers. Students said that they felt like "researchers or engineers and real teachers". They thought the lecturers were friendly and approachable, like team leaders or colleagues. Barriers seemed to disappear, and communication became easy. The lecturers also articulated their revised orientations. My role changes from a teacher, (I act as) a supervisor and as a consultant when they design something, I advise them to review their solutions. ANU Lecturer 2

Biggest change is that you are closer to the students, friendlier...in the classical one the students are far from you but in this you are sitting with them, talking, close face to face, discussing and you are like a friend rather than a teacher.. ANU Lecturer 3.

Changing one thing (pedagogy) ultimately means changing everything.

Staff responses to working with PBL were a mixture of both positive and negative. Whilst all interviewees said that they enjoyed working in this way they mostly all agreed it was a lot more work and higher risk. The broad framework presented in the Aalborg model was easy to conceptualise and follow, it was, a 'sticky' method, the framework we used is from the Aalborg PBL training in UK and when you are a practitioner it just clicks.

Lecturer 1 PPU but required more thought and structure than was at first realised. As the curriculum broadened to include practical applications and became process driven through the PBL approach, assessments also needed to be rethought. Lecturers remarked that the quality of work and engagement had increased but several realised they had to change the mode of assessment.

I also tweaked the assessment to ask them if they wanted to be evaluated as a team or individually. Also, peer evaluation and we discuss the assessment, so we introduced democracy to the grading process. ANU Lecturer 1. I changed the assessment so less writing and more technology-based products and presentations. PPT, videos. $B U$ Lecturer 3. Group working was problematic in some groups but groups that worked well together did better. It was the first time that I noticed students enjoying the work. PPU Lecturer 3

\section{Power relationships}

The PBL classes gave rise to a flatter structure where learning was negotiated. In some cases, the lecturers felt it was more democratic and the power dynamic in classes shifted. We loved the way that the student and the teacher are the same level. ANU Lecturer 3 It could also be argued that this change in pedagogical approach was a movement towards "constructing arts of living" by developing skills within students that resist being passive reception and create actors within society. Teaching people how to be 'agentic' within the bounds of their freedoms is always problematic but teachers realised the value in developing 'agentic' soft skills within their students. Seeing them collect data, engage with the texts, complain to me and fight sometimes with each other...that was a transformative experience for them. PPU Lecturer 2. They were structured around team work and dynamics and negotiations. It's worth it even if it fails. BU Lecturer 1 Some lecturers also saw the use of different spaces as a way of changing the footing of pedagogy (after Monahan 2002) and the dynamics of power in the classroom.

Class space is used for discussion... we have a round table, so I moved them to this room so that the space is different, so we are discussing the subject, they are free to talk and discuss. ANU Lecturer 1 However, PBL methods in Palestine as in other countries are working within a results based, content driven system. Barriers to implementation are systemic and revolved mainly around the difference in approach and whether students were receptive to it. 
We get an inflow of students that are very traditional with this type of lecturing - indoctrination, exam based. This continues in the university. The students put high pressure on their teachers against any new approach. It's challenging to move the students from teacher centred to student centred. It's not easy to change existing learning habits and expectations. Learning is harder this way. They expect you to transmit knowledge and when you flip the roles it's a bit of a shock. BU Lecturer 1

The PBL methodologies and cases at play in Palestine were broadly representative of the range within the Aalborg model. PBL also seemed to align with the needs and concerns of practitioners Royle and Hadfield (2012) where a technology (See Royle and Nikolic 2016) for a discussion of Technic (Teaching methods as Technology) is more likely to be adopted if it is aligned with teaching and learning concerns of practitioners. In this event there were four key attributes that PBL was able to tap into. The first was its simplicity, applicability and adaptability across a range of contexts. The simple Aalborg model asks lecturers to problematise existing courses rather than make courses anew, as such it is a bit of a 'Trojan Horse' as once started, other aspects of learning design require change as well. Second, there was a genuine desire to engage students who were demotivated. Lecturers were pleased by the increased levels of engagement. Third, there was a conscious need to develop critical thinking and collaborative skills within learners. I think it's a must in our education system because we need students who are problem solvers. I think it's a national thing... we need to create a nation of problem solvers. ANU Lecturer 3. Fourthly, the digital aspects and how PBL integrates them into practice (technology as tools for change) were useful in mitigating structural issues.

In a country like Palestine, because of the political situation for example Jerusalem on Tuesday there will be no transport and no classes, so we need alternatives so that education is not disrupted. In Palestine you are going to have days where movement is very difficult, but we need to continue. We live in a precarious environment and that's where technology plays a role. BU Lecturer 2

It can be seen that PBL is a pedagogy that opens space for change within previously orthodox practices in which students and lecturers can be actors and agents for change and it seems to promote deeper learning, (Fullan 2014), than the previous transmission models. Where PBL does initially open a 'smooth space' this space is quickly striated by scaffolding, however it is a loosely assembled striation with smoothness within it. As Allen (2009) notes,

There is no freedom without discipline, no vision without a form...If there were no lines painted on the road, you wouldn't be free to let your mind wander and be creative while you drive. You'd be too busy hoping no one hits you. But if there were too many lanes and restrictions and rules, you'd have traffic moving much slower than it should, as everyone was paying attention to being in the right place. (Allen 2009, p. 56).

At present however, PBL only opens small spaces within the greater confines of the orthodoxy, and it cannot get beyond this without a rethinking of curriculum at system level. Further work might use Savin Baden's ontology to position PBL as a cross discipline curriculum development or whole university initiative. This curriculum needs to link to the social context of Palestine directly and its young minds need to be directed to both thinking through and taking actions that solve the problems that are inherent within the developing society. If our ongoing task is to construct "arts of living" (after Foucault) it would seem that quite by accident rather than design in the Methods project, the manifold varieties but basic simplicities of PBL have chimed with the Palestinian spirit of collaborative endeavour and perhaps it is a potential Pedagogy for Palestine. As Gibson (1999) notes "That which is overdesigned, too highly specific, anticipates outcome; the anticipation of outcome guarantees, if not failure, the absence of grace." (Gibson 1999, p. 133)

Co-Funding . This research study was co-funded by the Erasmus+ Programme of the European Union, Erasmus+ Programme - METHODS Project number: 561940-EPP-1-2015-1-JO-EPPKA2-CBHE-JP, project title: Modernization of Teaching Methodologies in Higher Education: EU Experience for Jordan and Palestinian Territory (METHODS).

Disclaimer. This research project has been co-funded with support from the European Commission. This publication reflects the views only of the author, and the Commission cannot be held responsible for any use which may be made of the information contained therein. 
Acknowledgments. The author is grateful to Dr Wasel Ghanem (Birzeit University) who assisted with data collection in Palestine, the staff and students of Birzeit, Bethlehem, An Najah and Palestine Polytechnic University, Prof. Ahmed Al-Salaymeh the project General Coordinator-The University of Jordan and his assistant Lina Al-Marashdeh and all members of the project steering committee who added their insights and feedback.

\section{References}

Allen, D. (2009). Making it all work: Winning at the game of work and the business of life. New York: Penguin Books.

Bandura, A. (1982). The assessment and predictive generality of self-percepts of efficacy. Journal of Behavior Therapy and Experimental Psychiatry,13(3), 195-199. doi:10.1016/0005-7916(82)90004-0

Bandura, A. (2001). Social Cognitive Theory: An Agentic Perspective. Annual Review of Psychology Annu. Rev. Psychol.,52 (1), 1-26. doi:10.1146/annurev.psych.52.1.1

Bandura, A. (2006). Towards a Psychology of Human Agency. Perspectives on Psychological Science,1(2), 164-180. Retrieved December 28, 2018, from https://pdfs.semanticscholar.org/4c53/0339369cff0093101ba611b28e48620f3493.pdf.

Bayne, S. (2004). Smoothness and Striation in Digital Learning Spaces. E-Learning and Digital Media,1(2), 302-316. doi:10.2304/elea.2004.1.2.6

Bransford, J. D. (2004). How people learn: Brain, mind, experience, and school. Washington, DC: National Acad. Press.

Cauce, A. M., \& Gordon, E. W. (2013). Toward the Measurement of Human Agency and the Disposition to express it. Retrieved December 19, 2018, from https://www.ets.org/Media/Research/pdf/cauce_gordon_measurement_human_agency.pdf

Chilisa, B., \& Preece, J. (2005). Research methods for adult educators in Africa. Hamburg: UNESCO Inst. for Education.

Deleuze, G. \& Guattari, F. (1987) A Thousand Plateaus: Capitalism and Schizophrenia. London: Continuum.

Den Bossche, P. V., Gijselaers, W. H., Segers, M., \& Kirschner, P. A. (2006). Social and Cognitive Factors Driving Teamwork in Collaborative Learning Environments: Team Learning Beliefs and Behaviors. Small Group Research, 37(5), 490-521. https://doi.org/10.1177/1046496406292938

De Graff, E. and Kolmos, A. (2003). Characteristics of Problem-Based Learning. International Journal of Engineering Ed. Vol. 19, No. 5, pp. 657-662,

Edwards, A. (2007). Working Collaboratively to Build Resilience: A CHAT Approach. Social Policy and Society, 6, 255-265.

Foucault, M. (1975). Discipline and Punish: The Birth of the Prison, New York: Random House.

Foucault, M. (2000) Ethics. Essential works of Foucault, 1954-1984, vol. 1, P. Rabinow, ed.; R. Hurley et al., trans. (Harmondsworth, Penguin).

Fullan, M. \& Langworthy, M. (2014) A Rich Seam: How New Pedagogies Find Deep Learning, London: Pearson. 
Gee, J. P. (2005). What would a state of the art instructional video game look like? Innovate 1(6). Retrieved from http://www.innovateonline.info/index.php?view=article\&id=80

Gibson, W. (1999) All Tomorrows Parties. London: Penguin.

Hamilton, E. R., Rosenberg, J. M., \& Akcaoglu, M. (2016). The Substitution Augmentation Modification Redefinition (SAMR) Model: A Critical Review and Suggestions for its Use. TechTrends,60(5), 433-441. doi:10.1007/s11528-016-0091-y

Hampson, M. Patton, A. and Shanks, L. (2011) Ten Ideas for 21 st Century Education. London, Innovation Unit. Retrieved December 28, 2018, from https://www.innovationunit.org/wpcontent/uploads/2017/04/10-Ideas-for-21st-Century-Education.pdf

Kirkpatrick, D. L. (1996). Evaluating training programs: The four levels. San Francisco: BerrettKoehler.

Koehler, M. J., \& Mishra, P. (2009). What is technological pedagogical content knowledge? Contemporary Issues in Technology and Teacher Education, 9(1). Retrieved from https://www.citejournal.org/volume-9/issue-1-09/general/what-is-technologicalpedagogicalcontent-knowledge

Leadbeater, C. and Wong, A. (2010) Learning from the Extremes: A White Paper. San Jose, Calif., Cisco Systems Inc. Retrieved December 28, 2018, from http://charlesleadbeater.net/wpcontent/uploads/2010/05/LearningfromExtremes_WhitePaper.pdf

Leask, I. (2012) Beyond Subjection: Notes on the later Foucault and Education: Educational Philosophy and Theory, Vol. 44, No. S1.

Lee, M.J.W. and McLoughlin, C. (2007) Teaching and learning in the Web 2.0 era: empowering students through learner- generated content. International Journal of Instructional Technology \& Distance Learning, Vol. 4, No. 10, pp. 21-34. Retrieved December 28, 2018, from http://itdl.org/Journal/Oct_07/article02.htm

Magnussen, R. (2016). Methods Project Documents. (Unpublished)

Mertens, D. M. (2018). Mixed methods design in evaluation. Los Angeles: SAGE.

Monahan, T. (2002). "Flexible Space \& Built Pedagogy: Emerging IT Embodiments." Inventio 4 (1): $1-19$.

Ozdamar-Keskin, N., Ozata, F.Z., Banar, K. and Royle, K., (2015) Examining digital literacy competences and learning habits of open and distance learners, Contemporary Educational Technology, vol. 6, pp. 74-90

Osterlaken, I. (2015). Technology and human development. Oxford, UK: Routledge.

Pappe, I. (2018). Biggest Prison on Earth: A History of The Occupied Territories. S.1.: Oneworld publications.

Pólya, G. (1957). How to solve it: A new aspect of mathematical method. Garden City, NY: Doubleday \& Company.

Puentedura, R. R. (2006). The SAMR Model. Retrieved December 13, 2018, from http://hippasus.com/resources/tte/ 
Puentedura, R. (2014a). Building transformation: An introduction to the SAMR model [Blog post]. Retrieved February 4, 2019

from http://www.hippasus.com/rrpweblog/archives/2014/08/22/BuildingTransformation_AnIntroducti onToSAMR.pdf.

Roselli, N. D. (2016). Collaborative Learning: Theoretical Foundations and Applicable Strategies to University. Journal of Educational Psychology - Propositos Y Representaciones, 4(1), 251-280.

Retrieved December 28, 2018, from https://eric.ed.gov/?id=EJ1126307.

Royle., \& Hadfield, M. (2012). From 'Posh Pen and Pad' to Participatory Pedagogies.

International Journal of Mobile and Blended Learning,4 (1), 1-17. doi:10.4018/jmbl.2012010101

Royle, K., \& Nikolic, J. (2016). A modern mixture, Agency, Capability, Technology and 'Scrum': Agile Work Practices for Learning and Teaching in Schools. Journal of Education \& Social Policy, 3(3), 37-47. Retrieved December 19, 2018, from https://www.researchgate.net/publication/309764033_A_modern_mixture_Agency_Capability_Techn ology_and_Scrum'_Agile_Work_Practices_for_Learning_and_Teaching_in_Schools.

Savin-Baden, M. (2014). Using problem-based learning: New constellations for the 21st century. Journal on Excellence in College Teaching, 25(3\&4), 197-219.

Sen, A. (1985) Well-being, agency, and freedom. The Dewey Lectures 1984. The Journal of Philosophy, 82, 169-221.

Sen, A. (1992). Inequality Re-examined. Oxford, UK: Oxford University Press.

Thomas, J. W. (2000). A Review of Research on Project Based Learning. Retrieved from http://www.newtechnetwork.org.590elmp01.blackmesh.com/sites/default/files/dr/pblresearch2.pd

Tobias, S. (2005). Foucault on Freedom and Capabilities. Theory, Culture \& Society, 22(4), 65-85. doi:10.1177/0263276405053721

Trilling, B., \& Fadel, C. (2009) 21st century skills: Learning for life in our times. San Francisco, CA, US: Jossey-Bass.

Yahya, A. H. (2018). Tools for Internationalizing Higher Education in Developing Countries. The Future of Higher Education in the Middle East and Africa,87-103. doi:10.1007/978-3-319-64656-5_9 